\title{
Effect of Processing on Mungbean (Vigna radiata) Flour Nutritional Properties and Protein Composition
}

\author{
Daniel J. Skylas ${ }^{1,2}$, Mark P. Molloy ${ }^{3}$, Robert D. Willows ${ }^{3}$, Hayfa Salman ${ }^{1}$, \\ Christopher L. Blanchard ${ }^{2} \&$ Ken J. Quail ${ }^{1}$ \\ ${ }^{1}$ Australian Export Grains Innovation Centre, North Ryde, NSW, Australia \\ ${ }^{2}$ ARC Industrial Transformation Training Centre for Functional Grains, Charles Sturt University, Wagga Wagga, \\ NSW, Australia \\ ${ }^{3}$ Department of Chemistry and Biomolecular Sciences, Macquarie University, Sydney, Australia \\ Correspondence: Daniel J. Skylas, Australian Export Grains Innovation Centre, North Ryde, NSW, Australia. Tel: \\ 61-(0)2-8025-3200. E-mail: daniel.skylas@aegic.org.au
}

Received: May 29, 2018

doi:10.5539/jas.v10n11p16
Accepted: July 2, $2018 \quad$ Online Published: October 15, 2018

URL: https://doi.org/10.5539/jas.v10n11p16

\begin{abstract}
Pulses are traditionally processed prior to consumption, providing opportunities for modifying nutritional composition, dependant on the type of pulse and method used. In this study, we investigated the effect of whole seed, dehulling (dahl), germination and roasting on changes in mungbean flour nutritional properties, protein composition and relative protein abundance. Processed flours were analysed and compared for protein content, moisture, fat, ash, dietary fibre, total starch and amylose. Significant differences were imparted on dietary fibre content, with roasting and germination increasing the ratio of insoluble/soluble fibre as well as resistant starch. Comparative proteomic analysis resulted in a combined total of 539 protein identifications, searching against the Mungbean reference genome (NCBI Vigna radiata Annotation Release 100). Normalised spectral abundance factors were used as a measure of relative abundance and statistical analysis was applied (Students' T-Test), where proteins with a p-value of $<0.05$ considered significantly different. Processing imparted considerable changes to nutritional composition and should be further exploited for food applications. The comparative proteomic analyses carried out in this study proved useful for investigating the effect of processing on subsequent changes in protein composition and relative abundance.
\end{abstract}

Keywords: mungbean, processing, flour, nutrition, protein, proteomics

\section{Introduction}

Pulses can be used for enhancing the nutritional and functional properties of food, providing a source of protein, carbohydrate, dietary fibre, vitamins and minerals (Duranti \& Gius, 1997; Prakash et al., 2001; Tharanathan \& Mahadevamma, 2003; Boye et al., 2010; Nair et al., 2013; Vaz Patto et al., 2015). Major types of pulses grown in Australia include chickpea, faba bean, field pea, lentil, lupin and mungbean. The transformation of pulses from a commodity crop, to healthy value-added food ingredients, would benefit grain producers, processors and consumers. Promoting the health benefits of pulses, combined with improved nutritional qualities, functionality and diversity of food applications may lead to greater consumer acceptance, consumption and sustainable food production.

Mungbean (Vigna radiata) is primarily grown in rotation with cereals, delivering agronomic benefits, such as fixing atmospheric nitrogen into the soil. The majority of mungbean grown in Australia is exported (around 95\%), consisting predominantly of the large seeded Crystal variety, preferable for cooking and processing markets. Seed quality characteristics for export markets include size, colour, uniformity, varietal purity and protein content, which can vary depending on varietal performance, environment, agronomic practices and processing conditions. A review of the literature reported wide variation in protein content, averaging $23.8 \mathrm{~g} 100$ $\mathrm{g}^{-1}$ (Dahiya et al., 2015). Recently, a survey of Australian mungbean varieties grown in different regions reported

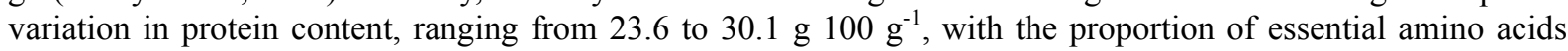
found to be highly conserved, comprising 38.1 to $38.7 \%$ of total protein (Skylas et al., 2017). 
Processing of pulses prior to consumption provides an opportunity for modifying nutritional properties, reducing the level of anti-nutritional factors, increasing protein digestibility and bioavailability of nutrients, as well as improving functionality, flavour and aroma (Tharanathan \& Mahadevamma, 2003; Vaz Patto et al., 2015; Patterson et al., 2017). Primary processing of pulses includes the more conventional methods such as soaking, dehulling, splitting and milling to flour for a range of applications. Secondary processing methods include a range of diverse treatments and include roasting, toasting, germination, fermentation and extrusion. Pulse flours can be further fractionated using wet or dry processes, for production of concentrated protein flours and isolates, which can also be modified to produce a range of functional ingredients (Fan \& Sosulski, 1974; Thompson, 1977; Rahma et al., 2000; Li et al., 2010; Wang et al., 2011; Pelgrom et al., 2015).

Proteomic technologies provide a range of methods for characterising changes in protein composition, relative abundance and protein identification (Thelen \& Peck, 2007; Matros et al., 2011). Aspects of this technology have previously been applied to mungbean for characterising changes in protein expression during seed development, germination and protein isolation (Ghosh \& Pal, 2012; Kazlowski et al., 2013; Skylas et al., 2017). Advances in comparative proteomics include 'label-free' quantitation known as spectral counting (SC), based on counting the number of spectra identified for peptides of specific proteins, used as a proxy for protein abundance (Lundgren et al., 2010; Neilson et al., 2013). Resulting spectra is then used to interrogate protein sequence databases to infer identification. Abundantly expressed proteins, such as seed storage proteins, will produce more spectra, resulting in more peptides belonging to that particular protein being identified, which is then used as a measure relative abundance (Liu et al., 2004; Zhang et al., 2006; Zybailov et al., 2007; Neilson et al., 2013). Improvements in the quality of SC data were made with the application of normalised spectral abundance factors (NSAFs), which are applied to account for the length of individual proteins, enabling comparison and statistical analysis of relative protein abundance (Zybailov et al., 2006; Zybailov et al., 2007; Mosley et al., 2009; Podwojski et al., 2010; Neilson et al., 2013; Mirzaei et al., 2016).

The objective of this study was to determine the effect of selected primary and secondary processes such as dehulling, germination and roasting on the nutritional composition of mungbean flours, as well as subsequent changes in protein composition and relative abundance. This study provides further knowledge of mungbean protein composition and subsequent changes associated from processing.

\section{Methods}

\subsection{Seed Material and Milling}

Mungbean whole seed, raw dahl and roasted dahl were commercially processed and provided by the Blue Ribbon Group (Richlands, QLD 4077), produced from the large seeded Crystal variety. For germination of whole seed material, seed was cleaned in absolute ethanol for $1 \mathrm{~min}$, then rinsed three times with water and drained. Fresh water was then added and seed material was allowed to soak and imbibe for 12 hours. Seeds were rinsed again, drained and germinated for 48 hours in an incubator (at $22^{\circ} \mathrm{C}$ ). Germinated seeds (including hulls) were oven dried $\left(50^{\circ} \mathrm{C}\right)$ and thrashed over a $2 \mathrm{~mm}$ sieve screen to dislodge seedling shoots, which were then separated and discarded. Seed material was milled to flour using an Alpine Pin Mill and designated herein as mungbean whole seed flour (MWF), raw dahl flour (MDF), roasted dahl flour (MRF) and germinated flour (MGF).

\subsection{Nutritional Composition}

Nutritional testing was carried out at the NATA accredited AEGIC Analytical Laboratory (Sydney) using approved standard methods of analysis. Testing was carried out in duplicate and the averaged result was reported. Nitrogen content was determined by the Dumas method using a LECO TruMac protein analyser (AOAC 992.23) and converted to protein $(\mathrm{N} \times 6.25)$. Standard methods used included ash; AOAC 923.03 and AACC 08-01.01, moisture; AOAC 925.10 and AACC 44-15.02, fat; AACC 30-10.01, and total dietary fibre (TDF; insoluble and soluble); AOAC 985.29 and 991.42. Starch was measured by Megazyme Starch Assay Kit (AOAC 996.11 and AACC 76-13.01). Resistant starch was measured by Megazyme Resistant Starch Assay Kit (AOAC 2002.02 and AACC 32-40.01).

\subsection{Comparative Proteomic Analysis}

The comparative proteomic methodology used in this study was the same as previously reported by the authors (Skylas et al., 2017). Flour samples were solubilised in $50 \mathrm{mM}$ TEAB containing $0.5 \%$ SDS and probe sonicated, reduced (using dithiothreitol) and alkylated (iodoacetamide). Samples were digested with trypsin for 16 hours at $37^{\circ} \mathrm{C}$ and SDS was removed from the digested samples using a detergent removal kit followed by a $\mathrm{C} 18$ clean up. Samples were dried down, resuspended in $0.1 \%$ formic acid and used for analysis. Analysis was carried out by 
reversed phase nano-LC directly coupled in line with a MS/MS system (LC-MS/MS). Samples from each fraction were separated over 90 minute gradients using an Easy Nano LC 1000 (Thermo Scientific). Samples (10 $\mu \mathrm{L}$ ) were injected onto an 'in house' packed solid core Halo C18 $100 \mu \mathrm{m} \times 3 \mathrm{~cm}$ peptide trap column and desalted with $20 \mu \mathrm{L}$ of $0.1 \%$ formic acid. The peptide trap was switched on line with the $\mathrm{C} 1875 \mu \mathrm{m} \times 10 \mathrm{~cm}$ analytical reversed phase column. Peptides were eluted from the column using a linear solvent gradient, step-wise from $5-25 \%$ of buffer [ $99.9 \%$ (v/v) acetonitrile, $0.1 \%(\mathrm{v} / \mathrm{v})$ formic acid] for $80 \mathrm{~min}, 25-85 \%$ of buffer for $2 \mathrm{~min}$ and then held at $85 \%$ for $8 \mathrm{~min}$ at a flow rate of $300 \mathrm{~L} / \mathrm{min}$ across the gradient.

The column eluate was directed into a nanospray ionization source of the QExactive mass spectrometer (ThermoScientific) and a $1.5 \mathrm{kV}$ electrospray voltage was applied via a liquid junction upstream of the column. Resulting spectra were scanned over the range 350-2000 amu. Automated peak recognition, dynamic exclusion, and MS/MS of the top ten most intense precursor ions at 30\% normalised collision energy were performed. The LC-MS/MS spectra were searched using the MS software Mascot (Matrix Science, London, UK), against the Mungbean reference genome (NCBI Vigna radiata Annotation Release 100) containing 35143 entries (Kang et al., 2014). Peptides were identified with a $1 \%$ false-discovery rate from a concatenated forward-reversed database search. Significant peptide matches were exported and samples compared using NSAF with the program referred to as "SCRappy" (Neilson et al., 2013). Proteins with p-values $<0.05$ following Student's T-Test of NSAF were considered significantly different between groups.

\section{Results and Discussion}

\subsection{Nutritional Composition of Processed Mungbean Flours}

Nutritional composition of respective mungbean flours (MWF, MDF, MRF and MGF) were analysed in duplicate and the average result for each nutritional component is reported in Table 1. The process of dehulling removes the outer seed coat from the cotyledon, which reportedly comprises $\sim 12 \%$ of dry seed weight (Singh et al., 1968), producing dahl with improved palatability and cooking time, used in a range of food applications. The effect of dehulling on nutritional composition was determined by comparison of MWF and MDF, primarily

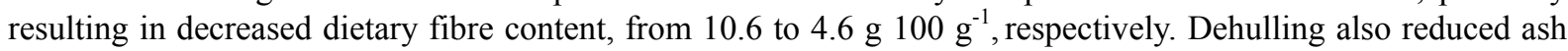
content, by removal of mineral content present in the outer seed coat. The effect of germination on nutritional composition was determined by comparison of MWF and MGF, with germination increasing protein and dietary fibre content, altering the ratio of insoluble (IDF) to soluble dietary fibre (SDF). Changes in the dietary fibre content most likely resulting from enzymatic modification of cell wall polysaccharides during germination, consistent with previous reports of increased crude fibre in lupins and dietary fibre in peas (Martín-Cabrejas et al., 2003; James et al., 2012). However, changes in nutritional composition can be partly attributed to decreased starch content, resulting from enzyme hydrolysis during germination, required to provide a source of energy for the emerging seedling. The proportion of amylose in starch also decreased in MGF, with similar findings observed for germinated lentil and horsegram flours (Ghumman et al., 2016). Roasting is often used for enhancing nutritional qualities, flavour and aroma, with the effect on nutritional composition determined by comparison of MDF and MRF. Roasting imparted significant changes in the ratio of IDF/SDF, increasing from 2.5 to 16, for MDF and MRF, respectively. The increased resistant starch content of MRF is most likely due to high-temperature induced modification of starch structure, increasing resistance to starch-degrading enzymes ( $\mathrm{Li}$ et al., 2011).

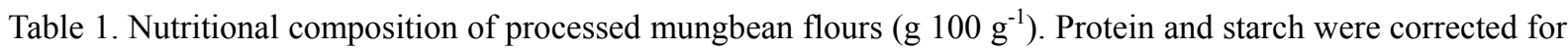
moisture content and reported on a dry basis

\begin{tabular}{lllll}
\hline Composition & MWF & MDF & MRF & MGF \\
\hline Protein & 27.6 & 28.3 & 27.8 & 29.4 \\
Moisture & 9.9 & 11.3 & 5.9 & 6.0 \\
Fat & 1.9 & 1.8 & 2.0 & 2.0 \\
Ash & 3.5 & 3.1 & 3.1 & 3.2 \\
\hline Dietary fibre: & & & & 13.1 \\
TDF & 10.6 & 4.6 & 3.4 & 11.6 \\
IDF & 7.6 & 3.3 & 3.2 & 1.5 \\
SDF & 3.0 & 1.3 & 0.2 & 7.7 \\
IDF/SDF ratio & 2.5 & 2.5 & 16 & 4.0 \\
Resistant starch & 3.0 & 0.7 & 14.6 & 42.6 \\
Starch & 45.4 & 53.1 & 51.9 & 33.1 \\
Amylose (\%) & 37.6 & 39.4 & 38.4 & \\
\hline
\end{tabular}




\subsection{Comparative Proteomic Analysis of Processed Mungbean Flours}

A comparative proteomic approach was applied to the representative processed flour samples, in order to investigate the effect of dehulling, germination and roasting on changes in protein composition and relative protein abundance. A combined total of 539 proteins were identified in the processed flours, with the distribution of these proteins between flours represented by a four-way Venn diagram (Figure 1). From this total, 72 proteins were classified as common, being present in MWF, MDF, MRF and MGF. Inferred protein identifications were reported in terms of matching protein description, identifiable database accession, average SC and NSAFs, as well as the ratio of NSAFs between two flour samples, used as measure of relative abundance. Statistical analyses (Student's T-Test) of NSAFs was applied, and proteins with a p-value $<0.05$ considered significantly different in abundance. The dataset was filtered, by removal of inferred protein identifications containing $<5 \mathrm{SC}$, except for those comparisons in which one sample contained $>5 \mathrm{SC}$. The absence of a specific protein in any sample does not conclusively mean that protein is not present, but only that the abundance level is too low to be detected on 5 or more occasions (as specified by our reporting criteria).

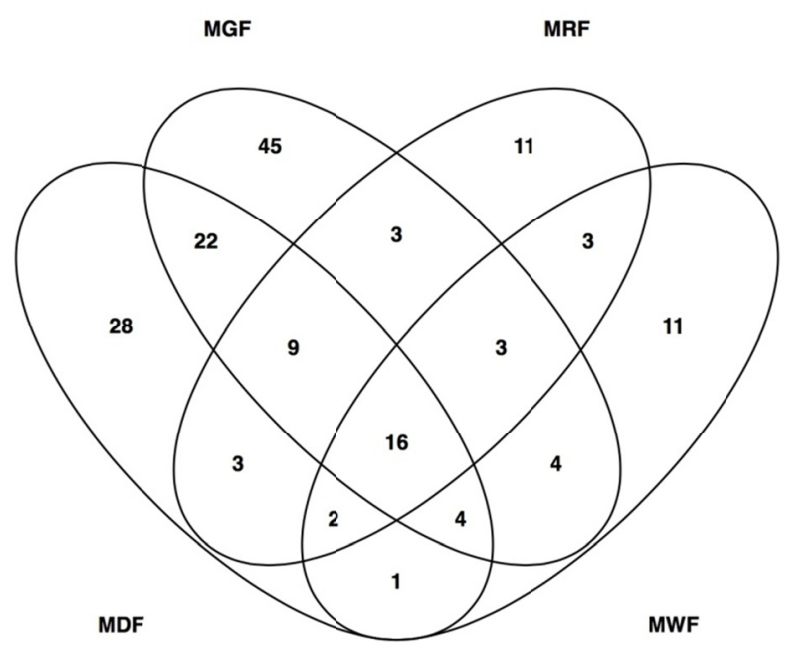

Figure 1. Four-way Venn diagram representing the distribution of identified proteins between processed mungbean flours (MWF, MDF, MRF and MGF)

\subsection{Effect of Dehulling on Protein Composition and Relative Abundance}

The effect of dehulling on protein composition and relative abundance was determined by comparison of proteins identified for MWF (95 proteins) and MDF (164 proteins). Of these proteins, 88 were classified as common, in which 27 were found to be significantly different in relative abundance, reported in Table 2, sorted in descending order of NSAFs. Identified proteins classified as specific for either MWF or MDF are listed in Appendix A. The most abundant proteins identified were the globulin storage proteins, which comprise mostly of the $8 \mathrm{~S}$, and to a lesser extent $11 \mathrm{~S}$ and $7 \mathrm{~S}$ globulins, reportedly having high sequence homology to soybean conglycinin and storage proteins from other pulses (Mendoza et al., 2001; Bernardo et al., 2004; Liu et al., 2015). Storage proteins, reported in Table 2, were predominantly identified as beta-conglycinin beta chain-like, with some found to be significantly different in relative abundance between the two flours. Changes in abundance of storage proteins could be attributed to the increased protein content of MDF compared to MWF (Table 1).

Another group of proteins found to be abundant were the late embryogenesis abundant (LEA) proteins, which accumulate in the seed embryo, playing a protective role through protein-protein interactions, in response to water deficit related stress and seed dehydration (Battaglia \& Covarrubias, 2013). There were six matches to this group of proteins, consisting of three different types (LEA type D-29, D-34 and 2), with the majority of these proteins being more abundant in MWF, two of which were significantly different. This may result from the loss of seed embryo tissue during the dehulling and kibbling process, resulting in the reduction of embryonic proteins in MDF. This is further supported by two other embryonic proteins (DC-8-like), which were found to be less abundant in MDF. 


\subsection{Effect of Germination on Protein Composition and Relative Abundance}

During the germination process, increased enzyme activity leads to modification of nutritional composition, resulting from hydrolysis of macronutrients such as starch and protein (Nout \& Ngoddy, 1997). This process can be used to enhance nutritional composition, resulting in increased protein solubility and digestibility (James et al., 2012). The effect of germination on protein composition and relative abundance was determined by comparison of proteins identified for MWF (95 proteins) and MGF (169 proteins). Of these proteins, 85 were classified as common, in which, 27 were found to be significantly different in relative abundance, reported in Table 3, sorted in descending order of NSAFs. Identified proteins classified as specific for either MWF or MGF are listed in Appendix B.

Of those proteins that were significantly different between MGF and MDF, there were 6 enzymes, involved in metabolism, which were more abundant in MGF. These included enzymes involved in starch degradation and carbon metabolism, including alpha-1,4 glucan phophorylase, UTP-glucose-1-phosphate uridylyltransferase, fructose-bisphosphate aldolase and ATPase (subunit 1). The other two enzymes included seed linoleate 9S-lipoxygenase, involved in fatty acid metabolism (Aanangi et al., 2016) and nudix hydrolase 3-like, which is involved in hydrolysis of a wide range of organic pyrophosphates and has been implicated to play a role in germination of Arabidopsis (Zeng et al., 2014). Other enzymes involved in metabolism, detected only in MGF (Appendix B), were glyceraldehyde-3-phosphate dehydrogenase, malate dehydrogenase, fructokinase-2-like and enolase.

Heat shock proteins (HSP) were also found to be significantly different between MGF and MDF. These proteins act as molecular chaperones, assisting in cellular processes including folding, assembly and degradation of proteins, as well as stabilisation and refolding of proteins in response to stress related conditions (Wang et al., 2004). HSPs found to be more abundant in MGF included HSP $70 \mathrm{kDa}$, HSP cognate $70 \mathrm{kDa}$ protein 2 and HSP 83. The HSP cognate $70 \mathrm{kDa}$ protein had the second highest ratio of NSAFs between MGF/MDF (at 7.28714), with the luminal-binding protein, also thought to function as a chaperone, having the highest ratio of NSAFs (at 7.64959). This is indicative of these proteins playing a crucial role in protein synthesis and degradation during the early stages of germination. Small HSPs $(17.6 \mathrm{kDa})$ have previously been identified in germinated mungbean cotyledons, also thought to play a protective role during this process (Ghosh \& Pal, 2012).

\subsection{Effect of Roasting on Protein Composition and Relative Abundance}

High temperatures required for roasting can partially denature, aggregate and modify protein structures, including glycation of lysine and free amines, resulting from Maillard reactions (Walker \& Kochhar, 1982; Sun-Waterhouse et al., 2014; Wang et al., 2016). Such protein modifications may reduce the potential number of tryptic peptides generated during the protein digestion step, carried out prior to LC-MS/MS, potentially leading to an under-estimation of the relative abundance of these proteins, compared to raw or non-roasted samples. The effect of roasting on protein composition and relative abundance was determined by comparison of proteins identified for MDF (164 proteins) and MRF (111 proteins). Of these proteins, 105 were classified as common, in which, 14 were found to be significantly different in relative abundance, reported in Table 4, sorted in descending order of NSAFs. Identified proteins classified as specific for either MWF or MRF are listed in Appendix C.

Table 2. Inferred identity and relative abundance of those proteins classified as common for MDF and MWF. NSAF ratios of MDF/MWF that are statistically significant $(\mathrm{p}<0.05)$ are highlighted in bold

\begin{tabular}{|c|c|c|c|c|c|c|}
\hline \multirow{2}{*}{ Identifier } & \multicolumn{2}{|c|}{ SC } & \multirow{2}{*}{$\begin{array}{l}\text { Matching protein description } \\
{[\text { Vigna radiata } \text { var. } \text { radiata }]}\end{array}$} & \multicolumn{2}{|c|}{ NSAF } & \multirow{2}{*}{$\frac{\text { Ratio }}{\text { MDF/MWF }}$} \\
\hline & MDF & MWF & & MDF & MWF & \\
\hline gi|951066354|ref|XP_014523937.1| & 557 & 250 & Beta-conglycinin, beta chain-like isoform X1 & 0.09288 & 0.11023 & 0.84260 \\
\hline gi|951067727|ref|XP_014524354.1| & 546 & 236 & Beta-conglycinin, beta chain-like & 0.09161 & 0.10434 & 0.87801 \\
\hline gi|951002540|ref|XP_014507363.1| & 334 & 147 & Beta-conglycinin, beta chain-like & 0.05910 & 0.06893 & 0.85740 \\
\hline gi|950940165|ref|XP_014492536.1| & 307 & 91 & Beta-conglycinin, beta chain-like & 0.05389 & 0.04237 & 1.27177 \\
\hline gi|951033982|ref|XP_014515878.1| & 252 & 84 & Beta-conglycinin, beta chain-like & 0.04225 & 0.03746 & 1.12777 \\
\hline gi|951056419|ref|XP_014521758.1| & 336 & 108 & Glycinin G4-like & 0.04171 & 0.03576 & 1.16650 \\
\hline gi|951066351|ref|XP_014523936.1| & 261 & 56 & Beta-conglycinin, alpha $\sim$ chain-like & 0.03694 & 0.02102 & 1.75759 \\
\hline gi|951023258|ref|XP_014513134.1| & 83 & 29 & Albumin-2-like & 0.02841 & 0.02696 & 1.05354 \\
\hline gi|951066358|ref|XP_014523938.1| & 152 & 130 & Beta-conglycinin, beta chain-like isoform $\mathrm{X} 2$ & 0.02525 & 0.05784 & 0.43648 \\
\hline gi|950930231|ref|XP_014503883.1| & 71 & 35 & Dehydrin DHN3-like & 0.02326 & 0.03062 & 0.75981 \\
\hline gi|950951134|ref|XP_014495577.1| & 66 & 33 & Embryonic protein DC-8-like & 0.01723 & 0.02303 & 0.74844 \\
\hline gi|950951230|ref|XP_014495608.1| & 22 & 15 & $18 \mathrm{kDa}$ seed maturation protein-like & 0.01711 & 0.03232 & 0.52929 \\
\hline
\end{tabular}




\begin{tabular}{|c|c|c|c|c|c|c|}
\hline \multirow{2}{*}{ Identifier } & \multicolumn{2}{|c|}{$\mathrm{SC}$} & \multirow{2}{*}{$\begin{array}{l}\text { Matching protein description } \\
\text { [Vigna radiata } \text { var. radiata] }\end{array}$} & \multicolumn{2}{|c|}{ NSAF } & \multirow{2}{*}{$\frac{\text { Ratio }}{\text { MDF/MWF }}$} \\
\hline & MDF & MWF & & MDF & MWF & \\
\hline gi|951066718|ref|XP_014524029.1| & 42 & 28 & P24 oleosin isoform B & 0.01634 & 0.02827 & 0.57786 \\
\hline gi|951034870|ref|XP_014516158.1| & 19 & 16 & Protein SLE2 & 0.01555 & 0.03407 & 0.45645 \\
\hline gi|951005658|ref|XP_014508213.1| & 61 & 38 & Low quality protein: late embryogenesis abundant protein D-29 & 0.01231 & 0.02021 & 0.60907 \\
\hline gi|951042174|ref|XP_014518107.1| & 66 & 24 & Basic 7S globulin 2-like & 0.01230 & 0.01194 & 1.02980 \\
\hline gi|951067725|ref|XP_014524353.1| & 39 & 10 & Beta-conglycinin, beta chain-like, partial & 0.01218 & 0.00892 & 1.36493 \\
\hline gi|950959908|ref|XP_014497548.1| & 15 & 6 & Protein SLE1 isoform X1 & 0.01106 & 0.01151 & 0.96135 \\
\hline gi|951016290|ref|XP_014511078.1| & 67 & 27 & Embryonic protein DC-8-like & 0.01066 & 0.01138 & 0.93635 \\
\hline gi|951072910|ref|XP_014491941.1| & 14 & 6 & Non-specific lipid-transfer protein 1 & 0.00995 & 0.01262 & 0.78870 \\
\hline gi|951032441|ref|XP_014515393.1| & 18 & 8 & Desiccation protectant protein Lea14 homolog & 0.00964 & 0.01110 & 0.86838 \\
\hline gi|951006474|ref|XP_014508481.1| & 23 & 8 & 1-Cys peroxiredoxin & 0.00817 & 0.00764 & 1.06875 \\
\hline gi|950968931|ref|XP_014499690.1| & 86 & 12 & Seed linoleate 9S-lipoxygenase-3 & 0.00768 & 0.00281 & 2.72783 \\
\hline gi|951066347|ref|XP_014523935.1| & 22 & 19 & Late embryogenesis abundant protein D-34-like & 0.00754 & 0.01741 & 0.43320 \\
\hline gi|950974150|ref|XP_014500866.1| & 8 & 4 & Uncharacterised protein LOC106761813 & 0.00750 & 0.01079 & 0.69518 \\
\hline gi|950973966|ref|XP_014500828.1| & 6 & 5 & Uncharacterised protein LOC106761773 & 0.00741 & 0.01675 & 0.44233 \\
\hline gi|951021491|ref|XP_014512682.1| & 44 & 19 & Sucrose-binding protein-like & 0.00661 & 0.00772 & 0.85599 \\
\hline gi|951056290|ref|XP_014521723.1| & 21 & 12 & Uncharacterised protein LOC106778296 & 0.00658 & 0.01027 & 0.64056 \\
\hline gi|951000293|ref|XP_014506761.1| & 23 & 5 & Glucose and ribitol dehydrogenase homolog 1-like & 0.00651 & 0.00399 & 1.63155 \\
\hline gi|950985610|ref|XP_014503380.1| & 7 & 1 & Uncharacterised protein LOC106763730 & 0.00593 & 0.00298 & 1.99007 \\
\hline gi|951035730|ref|XP_014516424.1| & 10 & 2 & Nucleoside diphosphate kinase 1 & 0.00551 & 0.00391 & 1.40732 \\
\hline gi|950986379|ref|XP_014503555.1| & 10 & 5 & 17.5 kDa class I heat shock protein-like & 0.00512 & 0.00753 & 0.68041 \\
\hline gi|951023922|ref|XP_014513287.1| & 18 & 4 & Glucose and ribitol dehydrogenase homolog 1-like & 0.00511 & 0.00348 & 1.47009 \\
\hline gi|951040313|ref|XP_014517640.1| & 17 & 6 & Glucose and ribitol dehydrogenase homolog 1-like & 0.00481 & 0.00436 & 1.10382 \\
\hline gi|950969621|ref|XP_014499874.1| & 6 & 1 & Late embryogenesis abundant protein 2 & 0.00472 & 0.00221 & 2.13426 \\
\hline gi|951014217|ref|XP_014510496.1| & 36 & 8 & Heat shock $70 \mathrm{kDa}$ protein & 0.00448 & 0.00282 & 1.58885 \\
\hline gi|950950919|ref|XP_014495514.1| & 8 & 3 & $18 \mathrm{kDa}$ seed maturation protein-like & 0.00417 & 0.00478 & 0.87327 \\
\hline gi|950993033|ref|XP_014504815.1| & 20 & 7 & Alcohol dehydrogenase 1-like [Vigna radiata var. radiata] & 0.00416 & 0.00388 & 1.07190 \\
\hline gi|951048093|ref|XP_014519608.1| & 35 & 14 & Canavalin & 0.00398 & 0.00425 & 0.93506 \\
\hline gi|951022780|ref|XP_014513011.1| & 12 & 4 & Peroxygenase & 0.00389 & 0.00410 & 0.95109 \\
\hline gi|950943234|ref|XP_014493768.1| & 8 & 7 & Peptidyl-prolyl cis-trans isomerase 1 & 0.00383 & 0.00933 & 0.41080 \\
\hline gi|951023386|ref|XP_014513168.1| & 10 & 5 & Late embryogenesis abundant protein D-34-like isoform X1 & 0.00327 & 0.00502 & 0.65205 \\
\hline gi|951039676|ref|XP_014517471.1| & 9 & 4 & Late embryogenesis abundant protein 2-like & 0.00324 & 0.00386 & 0.84021 \\
\hline gi|950968907|ref|XP_014499686.1| & 36 & 9 & Seed linoleate 9S-lipoxygenase-2 & 0.00322 & 0.00212 & 1.51668 \\
\hline gi|951023264|ref|XP_014513135.1| & 10 & 1 & Uncharacterised protein LOC106771650 & 0.00317 & 0.00096 & 3.28547 \\
\hline gi|951040842|ref|XP_014517782.1| & 5 & 3 & 40S ribosomal protein $\mathrm{S} 14$ & 0.00308 & 0.00441 & 0.69921 \\
\hline gi|951023134|ref|XP_014513100.1| & 6 & 1 & UPF0098 protein TC_0109-like & 0.00306 & 0.00184 & 1.66134 \\
\hline gi|951065326|ref|XP_014523717.1| & 18 & 1 & Luminal-binding protein, partial & 0.00304 & 0.00052 & 5.81445 \\
\hline gi|951066326|ref|XP_014523928.1| & 23 & 16 & Beta-conglycinin, beta chain-like & 0.00294 & 0.00538 & 0.54616 \\
\hline gi|950925699|ref|XP_014494982.1| & 14 & 3 & Formate dehydrogenase 1, mitochondrial-like isoform X1 & 0.00279 & 0.00200 & 1.39739 \\
\hline gi|950973879|ref|XP_014500811.1| & 6 & 4 & Late embryogenesis abundant protein D-34-like & 0.00274 & 0.00467 & 0.58811 \\
\hline gi|950994560|ref|XP_014505167.1| & 13 & 2 & UTP--glucose-1-phosphate uridylyltransferase & 0.00233 & 0.00095 & 2.44624 \\
\hline gi|950974705|ref|XP_014500967.1| & 22 & 2 & Nudix hydrolase 3-like & 0.00233 & 0.00077 & 3.01850 \\
\hline gi|950933283|ref|XP_014511756.1| & 28 & 6 & Alpha-1,4 glucan phosphorylase L isozyme & 0.00223 & 0.00126 & 1.76041 \\
\hline gi|950951948|ref|XP_014495815.1| & 17 & 1 & Heat shock cognate $70 \mathrm{kDa}$ protein 2 & 0.00216 & 0.00050 & 4.33791 \\
\hline gi|950993253|ref|XP_014504861.1| & 9 & 1 & Fructose-bisphosphate aldolase, cytoplasmic isozyme & 0.00205 & 0.00109 & 1.88943 \\
\hline gi|950954866|ref|XP_014496519.1| & 5 & 3 & 40S ribosomal protein $\mathrm{S} 8$-like & 0.00193 & 0.00350 & 0.55184 \\
\hline gi|951021073|ref|XP_014512575.1| & 13 & 2 & Granule-bound starch synthase 1, chloroplastic/amyloplastic-like & 0.00169 & 0.00073 & 2.31510 \\
\hline gi|323149044|ref|YP_004222824.1| & 10 & 2 & ATPase subunit 1 (mitochondrion) & 0.00164 & 0.00102 & 1.60306 \\
\hline gi|950933029|ref|XP_014511428.1| & 7 & 2 & Actin-1-like & 0.00155 & 0.00153 & 1.01112 \\
\hline gi|950934982|ref|XP_014515635.1| & 13 & 2 & Heat shock protein 83 & 0.00149 & 0.00062 & 2.39935 \\
\hline gi|951072874|ref|XP_014491920.1| & 7 & 3 & $60 \mathrm{~S}$ ribosomal protein $\mathrm{L} 4$ & 0.00145 & 0.00160 & 0.90941 \\
\hline gi|951067792|ref|XP_014524384.1| & 6 & 5 & Seed biotin-containing protein SBP65-like & 0.00141 & 0.00333 & 0.42366 \\
\hline gi|950979939|ref|XP_014501963.1| & 8 & 3 & Protein disulfide-isomerase-like & 0.00119 & 0.00143 & 0.83318 \\
\hline gi|951028515|ref|XP_014514444.1| & 6 & 4 & Serine carboxypeptidase-like & 0.00100 & 0.00168 & 0.59728 \\
\hline gi|951027555|ref|XP_014514203.1| & 6 & 3 & ATP synthase subunit beta, mitochondrial & 0.00099 & 0.00135 & 0.73383 \\
\hline gi|950945335|ref|XP_014494232.1| & 9 & 6 & Poly [ADP-ribose] polymerase 3 & 0.00086 & 0.00162 & 0.53315 \\
\hline gi|950929466|ref|XP_014502187.1| & 11 & 8 & TSC22 domain family protein 1-like & 0.00081 & 0.00158 & 0.51206 \\
\hline gi|950975966|ref|XP_014501194.1| & 5 & 1 & Elongation factor 2 & 0.00053 & 0.00036 & 1.47814 \\
\hline gi|950963716|ref|XP_014498402.1| & 5 & 1 & Cell division cycle protein 48 homolog & 0.00049 & 0.00038 & 1.27505 \\
\hline
\end{tabular}


Table 3. Inferred identity and relative abundance of those proteins classified as common for MGF and MWF. NSAF ratios of MGF/MWF that are statistically significant $(\mathrm{p}<0.05)$ are highlighted in bold

\begin{tabular}{|c|c|c|c|c|c|c|}
\hline \multirow{2}{*}{ Identifier } & \multicolumn{2}{|c|}{ SC } & \multirow{2}{*}{$\begin{array}{l}\text { Matching protein description } \\
\text { [Vigna radiata } \text { var. radiata }]\end{array}$} & \multicolumn{2}{|c|}{ NSAF } & \multirow{2}{*}{$\frac{\text { Ratio }}{\text { MGF/MWF }}$} \\
\hline & MGF & MWF & & MGF & MWF & \\
\hline gi|951066354|ref|XP_014523937.1| & 487 & 250 & Beta-conglycinin, beta chain-like isoform X1 & 0.10618 & 0.11092 & 0.95726 \\
\hline gi|951067727|ref|XP_014524354.1| & 470 & 236 & Beta-conglycinin, beta chain-like & 0.10337 & 0.10500 & 0.98451 \\
\hline gi|951002540|ref|XP_014507363.1| & 306 & 147 & Beta-conglycinin, beta chain-like & 0.07087 & 0.06936 & 1.02176 \\
\hline gi|950940165|ref|XP_014492536.1| & 303 & 91 & Beta-conglycinin, beta chain-like & 0.06965 & 0.04264 & 1.63339 \\
\hline gi|951066358|ref|XP_014523938.1| & 280 & 130 & Beta-conglycinin, beta chain-like isoform X2 & 0.05960 & 0.05811 & 1.02567 \\
\hline gi|951066351|ref|XP_014523936.1| & 218 & 56 & Beta-conglycinin, alpha chain-like & 0.04027 & 0.02115 & 1.90342 \\
\hline gi|951033982|ref|XP_014515878.1| & 169 & 84 & Beta-conglycinin, beta chain-like & 0.03715 & 0.03770 & 0.98545 \\
\hline gi|951056419|ref|XP_014521758.1| & 209 & 108 & Glycinin G4-like & 0.03387 & 0.03598 & 0.94140 \\
\hline gi|951023258|ref|XP_014513134.1| & 69 & 29 & Albumin-2-like & 0.03112 & 0.02714 & 1.14675 \\
\hline gi|951072910|ref|XP_014491941.1| & 16 & 6 & Non-specific lipid-transfer protein 1 & 0.01517 & 0.01270 & 1.19439 \\
\hline gi|951067725|ref|XP_014524353.1| & 32 & 10 & Beta-conglycinin, beta chain-like, partial & 0.01355 & 0.00898 & 1.50821 \\
\hline gi|951005658|ref|XP_014508213.1| & 46 & 38 & Low quality protein: late embryogenesis abundant protein D-29 & 0.01201 & 0.02034 & 0.59024 \\
\hline gi|951042174|ref|XP_014518107.1| & 48 & 24 & Basic 7S globulin 2-like & 0.01169 & 0.01202 & 0.97246 \\
\hline gi|951006474|ref|XP_014508481.1| & 23 & 8 & 1-Cys peroxiredoxin & 0.01099 & 0.00769 & 1.42848 \\
\hline gi|950951134|ref|XP_014495577.1| & 24 & 33 & Embryonic protein DC-8-like & 0.00846 & 0.02317 & 0.36491 \\
\hline gi|950968931|ref|XP_014499690.1| & 74 & 12 & Seed linoleate 9S-lipoxygenase-3 & 0.00843 & 0.00283 & 2.97410 \\
\hline gi|951021491|ref|XP_014512682.1| & 39 & 19 & Sucrose-binding protein-like & 0.00777 & 0.00777 & 0.99942 \\
\hline gi|951056290|ref|XP_014521723.1| & 18 & 12 & Uncharacterised protein LOC106778296 & 0.00765 & 0.01033 & 0.73985 \\
\hline gi|950930231|ref|XP_014503883.1| & 17 & 35 & Dehydrin DHN3-like & 0.00731 & 0.03081 & 0.23738 \\
\hline gi|951069682|ref|XP_014490344.1| & 7 & 1 & Non-specific lipid-transfer protein 1-like & 0.00710 & 0.00340 & 2.08549 \\
\hline gi|951066718|ref|XP_014524029.1| & 13 & 28 & P24 oleosin isoform B & 0.00687 & 0.02846 & 0.24130 \\
\hline gi|951016290|ref|XP_014511078.1| & 33 & 27 & Embryonic protein DC-8-like & 0.00666 & 0.01146 & 0.58153 \\
\hline gi|950943234|ref|XP_014493768.1| & 10 & 7 & Peptidyl-prolyl cis-trans isomerase 1 & 0.00649 & 0.00939 & 0.69122 \\
\hline gi|951000293|ref|XP_014506761.1| & 18 & 5 & Glucose and ribitol dehydrogenase homolog 1-like & 0.00648 & 0.00401 & 1.61332 \\
\hline gi|950985610|ref|XP_014503380.1| & 6 & 1 & Uncharacterised protein LOC106763730 & 0.00638 & 0.00300 & 2.12371 \\
\hline gi|950986379|ref|XP_014503555.1| & 10 & 5 & $17.5 \mathrm{kDa}$ class I heat shock protein-like & 0.00637 & 0.00758 & 0.84019 \\
\hline gi|951023922|ref|XP_014513287.1| & 17 & 4 & Glucose and ribitol dehydrogenase homolog 1-like & 0.00635 & 0.00350 & 1.81425 \\
\hline gi|951035730|ref|XP_014516424.1| & 8 & 2 & Nucleoside diphosphate kinase 1 & 0.00544 & 0.00394 & 1.38196 \\
\hline gi|951014217|ref|XP_014510496.1| & 31 & 8 & Heat shock $70 \mathrm{kDa}$ protein & 0.00496 & 0.00284 & 1.75058 \\
\hline gi|950951230|ref|XP_014495608.1| & 4 & 15 & $18 \mathrm{kDa}$ seed maturation protein-like & 0.00475 & 0.03253 & 0.14606 \\
\hline gi|951032441|ref|XP_014515393.1| & 7 & 8 & Desiccation protectant protein Lea14 homolog & 0.00475 & 0.01117 & 0.42508 \\
\hline gi|951040313|ref|XP_014517640.1| & 13 & 6 & Glucose and ribitol dehydrogenase homolog 1-like & 0.00454 & 0.00439 & 1.03534 \\
\hline gi|951034870|ref|XP_014516158.1| & 4 & 16 & Protein SLE2 & 0.00452 & 0.03429 & 0.13190 \\
\hline gi|950993253|ref|XP_014504861.1| & 14 & 1 & Fructose-bisphosphate aldolase, cytoplasmic isozyme & 0.00428 & 0.00109 & 3.91765 \\
\hline gi|951040842|ref|XP_014517782.1| & 5 & 3 & 40S ribosomal protein $\mathrm{S} 14$ & 0.00404 & 0.00444 & 0.90995 \\
\hline gi|951065326|ref|XP_014523717.1| & 18 & 1 & Luminal-binding protein, partial & 0.00401 & 0.00052 & 7.64959 \\
\hline gi|950968907|ref|XP_014499686.1| & 33 & 9 & Seed linoleate 9S-lipoxygenase-2 & 0.00385 & 0.00214 & 1.80187 \\
\hline gi|950993033|ref|XP_014504815.1| & 14 & 7 & Alcohol dehydrogenase 1-like & 0.00375 & 0.00391 & 0.96008 \\
\hline gi|951022780|ref|XP_014513011.1| & 8 & 4 & Peroxygenase & 0.00366 & 0.00412 & 0.88662 \\
\hline gi|950951948|ref|XP_014495815.1| & 23 & 1 & Heat shock cognate $70 \mathrm{kDa}$ protein 2 & 0.00364 & 0.00050 & 7.28714 \\
\hline gi|950954866|ref|XP_014496519.1| & 7 & 3 & 40S ribosomal protein S8-like & 0.00354 & 0.00353 & 1.00317 \\
\hline gi|951048093|ref|XP_014519608.1| & 23 & 14 & Canavalin & 0.00338 & 0.00428 & 0.78992 \\
\hline gi|951066326|ref|XP_014523928.1| & 19 & 16 & Beta-conglycinin, beta chain-like & 0.00316 & 0.00541 & 0.58280 \\
\hline gi|950974705|ref|XP_014500967.1| & 21 & 2 & Nudix hydrolase 3-like & 0.00290 & 0.00078 & 3.73366 \\
\hline gi|950977676|ref|XP_014501534.1| & 6 & 3 & 14-3-3-like protein isoform $\mathrm{X} 1$ & 0.00269 & 0.00303 & 0.88821 \\
\hline gi|323149044|ref|YP_004222824.1| & 13 & 2 & ATPase subunit 1 (mitochondrion) & 0.00268 & 0.00103 & 2.60508 \\
\hline gi|950925699|ref|XP_014494982.1| & 9 & 3 & Formate dehydrogenase 1 , mitochondrial-like isoform X1 & 0.00259 & 0.00201 & 1.28961 \\
\hline gi|951066347|ref|XP_014523935.1| & 5 & 19 & Late embryogenesis abundant protein D-34-like & 0.00248 & 0.01751 & 0.14150 \\
\hline gi|950933283|ref|XP_014511756.1| & 22 & 6 & Alpha-1,4 glucan phosphorylase L isozyme & 0.00227 & 0.00127 & 1.78654 \\
\hline gi|951072874|ref|XP_014491920.1| & 8 & 3 & 60 S ribosomal protein $\mathrm{L} 4$ & 0.00215 & 0.00161 & 1.33832 \\
\hline gi|950934982|ref|XP_014515635.1| & 15 & 2 & Heat shock protein 83 & 0.00211 & 0.00062 & 3.39005 \\
\hline gi|950994560|ref|XP_014505167.1| & 9 & 2 & UTP--glucose-1-phosphate uridylyltransferase & 0.00196 & 0.00096 & 2.04212 \\
\hline gi|951027555|ref|XP_014514203.1| & 9 & 3 & ATP synthase subunit beta, mitochondrial & 0.00185 & 0.00136 & 1.35875 \\
\hline gi|950933029|ref|XP_014511428.1| & 5 & 2 & Actin-1-like & 0.00149 & 0.00154 & 0.97032 \\
\hline gi|950979939|ref|XP_014501963.1| & 7 & 3 & Protein disulfide-isomerase-like & 0.00135 & 0.00144 & 0.93825 \\
\hline gi|951028515|ref|XP_014514444.1| & 5 & 4 & Serine carboxypeptidase-like & 0.00104 & 0.00169 & 0.61560 \\
\hline gi|951021073|ref|XP_014512575.1| & 5 & 2 & Granule-bound starch synthase 1, chloroplastic/amyloplastic-like & 0.00096 & 0.00073 & 1.30544 \\
\hline
\end{tabular}




\begin{tabular}{|c|c|c|c|c|c|c|}
\hline \multirow{2}{*}{ Identifier } & \multicolumn{2}{|c|}{ SC } & \multirow{2}{*}{$\begin{array}{l}\text { Matching protein description } \\
\text { [Vigna radiata } \text { var. radiata }]\end{array}$} & \multicolumn{2}{|c|}{ NSAF } & \multirow{2}{*}{$\frac{\text { Ratio }}{\text { MGF/MWF }}$} \\
\hline & MGF & MWF & & MGF & MWF & \\
\hline gi|950952971|ref|XP_014496061.1| & 5 & 1 & Chaperone protein ClpB1 & 0.00065 & 0.00034 & 1.87751 \\
\hline gi|951023386|ref|XP_014513168.1| & 1 & 5 & Late embryogenesis abundant protein $\mathrm{D}$-34-like isoform $\mathrm{X} 1$ & 0.00063 & 0.00505 & 0.12566 \\
\hline gi|950945335|ref|XP_014494232.1| & 4 & 6 & Poly [ADP-ribose] polymerase 3 & 0.00057 & 0.00163 & 0.34738 \\
\hline gi|951067792|ref|XP_014524384.1| & 1 & 5 & Seed biotin-containing protein SBP65-like & 0.00056 & 0.00335 & 0.16606 \\
\hline gi|950929466|ref|XP_014502187.1| & 3 & 8 & TSC22 domain family protein 1-like & 0.00034 & 0.00159 & 0.21445 \\
\hline
\end{tabular}

Table 4. Inferred identity and relative abundance of those proteins classified as common for MDF and MRF. NSAF ratios of MDF/MRF that are statistically significant $(\mathrm{p}<0.05)$ are highlighted in bold

\begin{tabular}{|c|c|c|c|c|c|c|}
\hline \multirow{2}{*}{ Identifier } & \multicolumn{2}{|c|}{ SC } & \multirow{2}{*}{$\begin{array}{l}\text { Matching protein description } \\
{[\text { Vigna radiata var. radiata }]}\end{array}$} & \multicolumn{2}{|c|}{ NSAF } & \multirow{2}{*}{$\frac{\text { Ratio }}{\text { MDF/MRF }}$} \\
\hline & MDF & MRF & & MDF & MRF & \\
\hline gi|951066354|ref|XP_014523937.1| & 557 & 500 & Beta-conglycinin, beta chain-like isoform X1 & 0.09280 & 0.12154 & 0.76354 \\
\hline gi|951067727|ref|XP_014524354.1| & 546 & 475 & Beta-conglycinin, beta chain-like & 0.09154 & 0.11597 & 0.78930 \\
\hline gi|951066306|ref|XP_014523923.1| & 405 & 258 & Beta-conglycinin, beta chain-like & 0.08162 & 0.06543 & 1.24749 \\
\hline gi|951002540|ref|XP_014507363.1| & 334 & 309 & Beta-conglycinin, beta chain-like & 0.05905 & 0.07935 & 0.74414 \\
\hline gi|950940165|ref|XP_014492536.1| & 307 & 298 & Beta-conglycinin, beta chain-like & 0.05385 & 0.07568 & 0.71145 \\
\hline gi|951033982|ref|XP_014515878.1| & 252 & 193 & Beta-conglycinin, beta chain-like & 0.04222 & 0.04778 & 0.88347 \\
\hline gi|951056419|ref|XP_014521758.1| & 336 & 225 & Glycinin G4-like & 0.04168 & 0.04085 & 1.02034 \\
\hline gi|951066351|ref|XP_014523936.1| & 261 & 172 & Beta-conglycinin, alpha $\sim$ chain-like & 0.03691 & 0.03480 & 1.06069 \\
\hline gi|951023258|ref|XP_014513134.1| & 83 & 70 & Albumin-2-like & 0.02838 & 0.03518 & 0.80683 \\
\hline gi|951066358|ref|XP_014523938.1| & 152 & 287 & Beta-conglycinin, beta chain-like isoform X2 & 0.02524 & 0.06054 & 0.41695 \\
\hline gi|950930231|ref|XP_014503883.1| & 71 & 44 & Dehydrin DHN3-like & 0.02324 & 0.02101 & 1.10658 \\
\hline gi|950951134|ref|XP_014495577.1| & 66 & 29 & Embryonic protein DC-8-like & 0.01722 & 0.01126 & 1.52972 \\
\hline gi|950951230|ref|XP_014495608.1| & 22 & 11 & $18 \mathrm{kDa}$ seed maturation protein-like & 0.01709 & 0.01149 & 1.48757 \\
\hline gi|951066718|ref|XP_014524029.1| & 42 & 20 & P24 oleosin isoform B & 0.01632 & 0.01160 & 1.40759 \\
\hline gi|951034870|ref|XP_014516158.1| & 19 & 17 & Protein SLE2 & 0.01554 & 0.01962 & 0.79206 \\
\hline gi|951005658|ref|XP_014508213.1| & 61 & 9 & Low quality protein: late embryogenesis abundant protein D-29 & 0.01230 & 0.00259 & 4.75216 \\
\hline gi|951042174|ref|XP_014518107.1| & 66 & 51 & Basic 7S globulin 2-like & 0.01228 & 0.01387 & 0.88571 \\
\hline gi|951067725|ref|XP_014524353.1| & 39 & 38 & Beta-conglycinin, beta chain-like, partial & 0.01217 & 0.01699 & 0.71650 \\
\hline gi|950959908|ref|XP_014497548.1| & 15 & 7 & Protein SLE1 isoform X1 & 0.01105 & 0.00761 & 1.45160 \\
\hline gi|951016290|ref|XP_014511078.1| & 67 & 16 & Embryonic protein DC-8-like & 0.01065 & 0.00374 & 2.84737 \\
\hline gi|951072910|ref|XP_014491941.1| & 14 & 10 & Non-specific lipid-transfer protein 1 & 0.00994 & 0.01083 & 0.91830 \\
\hline gi|951032441|ref|XP_014515393.1| & 18 & 13 & Desiccation protectant protein Lea14 homolog & 0.00963 & 0.01016 & 0.94812 \\
\hline gi|951006474|ref|XP_014508481.1| & 23 & 8 & 1-Cys peroxiredoxin & 0.00816 & 0.00467 & 1.74620 \\
\hline gi|950968931|ref|XP_014499690.1| & 86 & 26 & Seed linoleate 9S-lipoxygenase-3 & 0.00767 & 0.00336 & 2.28334 \\
\hline gi|951066347|ref|XP_014523935.1| & 22 & 21 & Late embryogenesis abundant protein D-34-like & 0.00753 & 0.01026 & 0.73413 \\
\hline gi|950974150|ref|XP_014500866.1| & 8 & 5 & Uncharacterised protein LOC106761813 & 0.00750 & 0.00651 & 1.15148 \\
\hline gi|950973966|ref|XP_014500828.1| & 6 & 4 & Uncharacterised protein LOC106761773 & 0.00740 & 0.00768 & 0.96356 \\
\hline gi|951006538|ref|XP_014508498.1| & 11 & 2 & Uncharacterised protein LOC106768046 & 0.00695 & 0.00186 & 3.74767 \\
\hline gi|951021491|ref|XP_014512682.1| & 44 & 45 & Sucrose-binding protein-like & 0.00661 & 0.01016 & 0.64993 \\
\hline gi|951056290|ref|XP_014521723.1| & 21 & 10 & Uncharacterised protein LOC106778296 & 0.00657 & 0.00454 & 1.44907 \\
\hline gi|951000293|ref|XP_014506761.1| & 23 & 10 & Glucose and ribitol dehydrogenase homolog 1-like & 0.00651 & 0.00408 & 1.59331 \\
\hline gi|950985610|ref|XP_014503380.1| & 7 & 2 & Uncharacterised protein LOC106763730 & 0.00592 & 0.00262 & $\mathbf{2 . 2 5 7 7 7}$ \\
\hline gi|951035730|ref|XP_014516424.1| & 10 & 6 & Nucleoside diphosphate kinase 1 & 0.00550 & 0.00481 & 1.14333 \\
\hline gi|950986379|ref|XP_014503555.1| & 10 & 6 & $17.5 \mathrm{kDa}$ class I heat shock protein-like & 0.00512 & 0.00438 & 1.16784 \\
\hline gi|951023922|ref|XP_014513287.1| & 18 & 1 & Glucose and ribitol dehydrogenase homolog 1-like & 0.00511 & 0.00055 & 9.27724 \\
\hline gi|951040313|ref|XP_014517640.1| & 17 & 9 & Glucose and ribitol dehydrogenase homolog 1-like & 0.00481 & 0.00350 & 1.37506 \\
\hline gi|950969621|ref|XP_014499874.1| & 6 & 3 & Late embryogenesis abundant protein 2 & 0.00472 & 0.00379 & 1.24558 \\
\hline gi|951014217|ref|XP_014510496.1| & 36 & 3 & Heat shock $70 \mathrm{kDa}$ protein & 0.00447 & 0.00058 & 7.64503 \\
\hline gi|950950919|ref|XP_014495514.1| & 8 & 1 & $18 \mathrm{kDa}$ seed maturation protein-like & 0.00417 & 0.00112 & 3.72353 \\
\hline gi|950993033|ref|XP_014504815.1| & 20 & 3 & Alcohol dehydrogenase 1-like & 0.00416 & 0.00103 & 4.02609 \\
\hline gi|951048093|ref|XP_014519608.1| & 35 & 18 & Canavalin & 0.00397 & 0.00275 & 1.44546 \\
\hline gi|951022780|ref|XP_014513011.1| & 12 & 5 & Peroxygenase [Vigna radiata var. radiata] & 0.00389 & 0.00274 & 1.41912 \\
\hline gi|950943234|ref|XP_014493768.1| & 8 & 4 & Peptidyl-prolyl cis-trans isomerase 1 & 0.00383 & 0.00335 & 1.14194 \\
\hline gi|951023386|ref|XP_014513168.1| & 10 & 6 & Late embryogenesis abundant protein $\mathrm{D}$-34-like isoform $\mathrm{X} 1$ & 0.00327 & 0.00308 & 1.06164 \\
\hline gi|951039676|ref|XP_014517471.1| & 9 & 1 & Late embryogenesis abundant protein 2-like & 0.00324 & 0.00056 & 5.80070 \\
\hline gi|950968907|ref|XP_014499686.1| & 36 & 14 & Seed linoleate 9S-lipoxygenase- 2 & 0.00322 & 0.00180 & 1.79275 \\
\hline gi|951023264|ref|XP_014513135.1| & 10 & 3 & Uncharacterised protein LOC106771650 & 0.00317 & 0.00204 & 1.55016 \\
\hline gi|951040842|ref|XP_014517782.1| & 5 & 6 & 40S ribosomal protein $\mathrm{S} 14$ & 0.00308 & 0.00466 & 0.66011 \\
\hline
\end{tabular}




\begin{tabular}{|c|c|c|c|c|c|c|}
\hline \multirow{2}{*}{ Identifier } & \multicolumn{2}{|c|}{ SC } & \multirow{2}{*}{$\begin{array}{l}\text { Matching protein description } \\
{[\text { Vigna radiata } \text { var. radiata }]}\end{array}$} & \multicolumn{2}{|c|}{ NSAF } & \multirow{2}{*}{$\frac{\text { Ratio }}{\text { MDF/MRF }}$} \\
\hline & MDF & MRF & & MDF & MRF & \\
\hline gi|951023134|ref|XP_014513100.1| & 6 & 2 & UPF0098 protein TC_0109-like & 0.00306 & 0.00194 & 1.57800 \\
\hline gi|951065326|ref|XP_014523717.1| & 18 & 2 & Luminal-binding protein, partial & 0.00303 & 0.00045 & 6.77394 \\
\hline gi|951066326|ref|XP_014523928.1| & 23 & 24 & Beta-conglycinin, beta chain-like & 0.00294 & 0.00447 & 0.65718 \\
\hline gi|950925699|ref|XP_014494982.1| & 14 & 1 & Formate dehydrogenase 1, mitochondrial-like isoform X1 & 0.00279 & 0.00036 & 7.69934 \\
\hline gi|950973879|ref|XP_014500811.1| & 6 & 4 & Late embryogenesis abundant protein D-34-like & 0.00274 & 0.00301 & 0.91121 \\
\hline gi|951042601|ref|XP_014518193.1| & 6 & 4 & Uncharacterised GPI-anchored protein At5g19250-like & 0.00243 & 0.00283 & 0.85912 \\
\hline gi|950994560|ref|XP_014505167.1| & 13 & 1 & UTP--glucose-1-phosphate uridylyltransferase & 0.00233 & 0.00030 & 7.77599 \\
\hline gi|950974705|ref|XP_014500967.1| & 22 & 9 & Nudix hydrolase 3-like & 0.00233 & 0.00155 & 1.50251 \\
\hline gi|950933283|ref|XP_014511756.1| & 28 & 8 & Alpha-1,4 glucan phosphorylase L isozyme & 0.00222 & 0.00097 & 2.28607 \\
\hline gi|950951948|ref|XP_014495815.1| & 17 & 1 & Heat shock cognate $70 \mathrm{kDa}$ protein 2 & 0.00215 & 0.00025 & 8.59277 \\
\hline gi|950933402|ref|XP_014511960.1| & 12 & 5 & Elongation factor 1-alpha & 0.00212 & 0.00146 & 1.45311 \\
\hline gi|951036864|ref|XP_014516740.1| & 6 & 1 & 40S ribosomal protein S6-like & 0.00208 & 0.00093 & 2.22807 \\
\hline gi|950993253|ref|XP_014504861.1| & 9 & 3 & Fructose-bisphosphate aldolase, cytoplasmic isozyme & 0.00205 & 0.00140 & 1.46107 \\
\hline gi|950954866|ref|XP_014496519.1| & 5 & 5 & 40S ribosomal protein S8-like & 0.00193 & 0.00272 & 0.71008 \\
\hline gi|950944995|ref|XP_014494154.1| & 7 & 1 & Malate dehydrogenase, mitochondrial & 0.00171 & 0.00064 & 2.68187 \\
\hline gi|951021073|ref|XP_014512575.1| & 13 & 4 & Granule-bound starch synthase 1, chloroplastic/amyloplastic-like & 0.00169 & 0.00091 & 1.85532 \\
\hline gi|323149044|ref|YP_004222824.1| & 10 & 2 & ATPase subunit 1 (mitochondrion) & 0.00164 & 0.00061 & 2.68466 \\
\hline gi|950933029|ref|XP_014511428.1| & 7 & 2 & Actin-1-like & 0.00155 & 0.00081 & 1.91189 \\
\hline gi|950934982|ref|XP_014515635.1| & 13 & 1 & Heat shock protein 83 & 0.00148 & 0.00020 & 7.54676 \\
\hline gi|951072874|ref|XP_014491920.1| & 7 & 6 & $60 \mathrm{~S}$ ribosomal protein $\mathrm{L} 4$ & 0.00145 & 0.00170 & 0.85444 \\
\hline gi|950979939|ref|XP_014501963.1| & 8 & 2 & Protein disulfide-isomerase-like & 0.00119 & 0.00044 & 2.72129 \\
\hline gi|950929654|ref|XP_014502725.1| & 3 & 5 & 40S ribosomal protein $\mathrm{S} 3$-1-like & 0.00114 & 0.00295 & 0.38647 \\
\hline gi|951028515|ref|XP_014514444.1| & 6 & 5 & Serine carboxypeptidase-like & 0.00100 & 0.00103 & 0.97390 \\
\hline gi|951027555|ref|XP_014514203.1| & 6 & 3 & ATP synthase subunit beta, mitochondrial & 0.00099 & 0.00066 & 1.50343 \\
\hline gi|950945335|ref|XP_014494232.1| & 9 & 1 & Poly [ADP-ribose] polymerase 3 & 0.00086 & 0.00028 & 3.13469 \\
\hline gi|950929466|ref|XP_014502187.1| & 11 & 3 & TSC22 domain family protein 1 -like & 0.00081 & 0.00034 & 2.41113 \\
\hline gi|950975966|ref|XP_014501194.1| & 5 & 1 & Elongation factor 2 & 0.00053 & 0.00028 & 1.88891 \\
\hline
\end{tabular}

\section{Conclusion}

The main objectives of this study were to expand our knowledge and understanding of the effect of specific processing conditions on nutritional composition of mungbean flours, as well as providing significant and comprehensive analyses of mungbean protein composition and relative abundance using a comparative proteomic approach. Processing methods used in this study imparted significant changes to mungbean nutritional composition, leading to altered functionality and potential end-use applications. Investigating the effect of processing conditions on protein composition and relative abundance is important for the production of functional, value-added high protein fractions for food applications. Innovative processing methods applied to mungbean and other pulse flours, combined with advanced proteomic tools for characterising protein composition and relative abundance, will provide an effective platform for developing concentrated protein flours and isolates. This study paves the way for further work focussing on the production of functional flours with enhanced digestibility and bioavailability of nutrients. Enhanced nutritional qualities and promotion of the health benefits of pulse products could potentially lead to wider consumer acceptance and increased sustainability for future food production.

\section{Acknowledgements}

I would like to acknowledge the work carried out by the Analytical Laboratory team at the Australian Export Grains Innovation Centre in Sydney. Part of this work was undertaken at APAF with the infrastructure provided by the Australian Government through the National Collaborative Research Infrastructure Strategy (NCRIS).

\section{References}

Aanangi, R., Kotapati, K. V., Palaka, B. K., Kedam, T., Kanika, N. D., \& Ampasala, D. R. (2016). Purification and characterization of lipoxygenase from mungbean (Vigna radiata L.) germinating seedlings. 3 Biotech, 6, 1-8. https://doi.org/10.1007/s13205-016-0427-5

Battaglia, M., \& Covarrubias, A. A. (2013). Late embryogenesis abundant (LEA) proteins in legumes. Frontiers in Plant Science, 4, 1-11. https://doi.org/10.3389/fpls.2013.00190

Bernardo, A. E. N., Garcia, R. N., Adachi, M., \& Tecson-Mendoza, E. M. (2004). 8S globulin of mungbean (Vigna radiata (L.) Wilczek): Cloning and characterisation of its cDNA isoforms, expression in Escherichia 
coli, purification, and crystallisation of the major recombinant $8 \mathrm{~S}$ isoform. Journal of Agricultural and Food Chemistry, 52, 2552-2560. https://doi.org/10.1021/jf0305938

Boye, J., Zare, F., \& Pletch, A. (2010). Pulse proteins: Processing, characterisation, functional properties and applications in food and feed. Food Research International, 43, 414-431. https://doi.org/10.1016/j.foodres. 2009.09.003

Dahiya, P. K., Linnemann, A. R., Van Boekel, M. A. J. S., Khetarpaul, N., Grewal, R. B., \& Nout, M. J. R. (2015). Mungbean: technological and nutritional potential. Critical Reviews in Food Science and Nutrition, 55, 670-688. https://doi.org/10.1080/10408398.2012.671202

Duranti, M., \& Gius, C. (1997). Legume seeds: Protein content and nutritional value. Field Crops Research, 53, 31-45. https://doi.org/10.1016/S0378-4290(97)00021-X

Fan, T. Y., \& Sosulski, F. W. (1974). Dispersibility and isolation of proteins from legume flours. Canadian Institute of Food Science and Technology Journal, 7, 256-261. https://doi.org/10.1016/S0315-5463(74) 73923-2

Ghosh, S., \& Pal, A. (2012). Identification of differential proteins of mungbean cotyledons during seed germination. Acta Physiologiae Plantarum, 34, 2379-2391. https://doi.org/10.1007/s11738-012-1042-7

Ghumman, A., Kaur, A., \& Singh, N. (2016). Impact of germination on flour, protein and starch characteristics of lentil (Lens culinari) and horsegram (Macrotyloma uniflorum L.) lines. LWT-Food Science and Technology, 65, 137-144. https://doi.org/10.1016/j.lwt.2015.07.075

James, A., Jayasena, V., \& Rumiyati. (2012). Effect of germination on the nutritional and protein profile of Australian sweet lupin (Lupinus angustifolius L.). Food and Nutrition Sciences, 3, 621-626. https://doi.org/ 10.4236/fns.2012.35085

Kang, Y. J., Kim, S. K., Kim, M. J., Lestari, P., Kim, K. H., Ha, B.-K., ... Lee, S.-H. (2014). Genome sequence of mungbean and insights into evolution within Vigna species. Nature Communications, 5, 1-9. https://doi.org/10.1038/ncomms6443

Kazlowski, B., Chen, M.-R., Chao, P.-M., Lai, C.-C., \& Ko, Y.-T. (2013). Identification and roles of proteins for seed development in mungbean (Vigna radiata L.) seed proteomes. Journal of Agricultural and Food Chemistry, 61, 6650-6659. https://doi.org/10.1021/jf401170g

Li, S., Ward, R., \& Gao, Q. (2011). Effect of heat-moisture treatment on the formation and physicochemical properties of resistant starch from Mungbean (Phaseolus radiatus) starch. Food Hydrocolloids, 25, 1702-1709. https://doi.org/10.1016/j.foodhyd.2011.03.009

Li, W., Shu, C., Yan, S., \& Shen, Q. (2010). Characteristics of sixteen mungbean cultivars and their protein isolates. International Journal of Food Science and Technology, 45, 1205-1211. https://doi.org/10.1111/ j.1365-2621.2010.02259.x

Liu, H., Liu, H., Yan, L., Cheng, X., \& Kang, Y. (2015). Functional properties of 8S globulin fractions from 15 mungbean (Vigna radiata (L.) Wilczek) cultivars. International Journal of Food Science and Technology, 50, 1206-1214. https://doi.org/10.1111/ijfs.12761

Liu, H., Sadygov, R. G., \& Yates J. R. (2004). A model for random sampling and estimation of relative protein abundance in shotgun proteomics. Analytical Chemistry, 76, 4193-4201. https://doi.org/10.1021/ac0498563

Lundgren, D. H., Hwang, S., Wu, L., \& Han, D. K. (2010). Role of spectral counting in quantitative proteomics. Expert Reviews in Proteomics, 7, 39-53. https://doi.org/10.1586/epr.09.69

Martín-Cabrejas, M. A., Ariza, N., Esteban, R., Mollá, E., Waldron, K., \& López-Andréu, F. J. (2003). Effect of germination on the carbohydrate composition of the dietary fiber of peas (Pisum sativum L.). Journal of Agricultural and Food Chemistry, 51, 1254-1259. https://doi.org/10.1021/jf0207631

Matros, A., Kaspar, S., Witzel, K., \& Mock, H. P. (2011). Recent progress in liquid chromatography-based separation and label-free quantitative plant proteomics. Phytochemistry, 72, 963-974. https://doi.org/ 10.1016/j.phytochem.2010.11.009

Mendoza, E. M. T., Adachi, M., Bernardo, A. E. N., \& Utsumi, S. (2001). Mungbean (Vigna radiata (L.) Wilczek) globulins: Purification and characterisation. Journal of Agricultural and Food Chemistry, 49, 1552-1558. https://doi.org/10.1021/jf001041h 
Mirzaei, M., Wu, Y., Handler, D., Maher, T., Pascovici, D., Ravishankar, P., ... Willows, R. D. (2016). Applications of quantitative proteomics in plant research. In G. H. Salekdeh (Ed.), Agricultural Proteomics (Vol. 1, pp. 1-23). Springer International Publishing Switzerland. https://doi.org/10.1007/978-3-31943275-5 1

Mosley, A. L., Florens, L., Wen, Z., \& Washburn, M. P. (2009). A label free quantitative proteomic analysis of the Saccharomyces cerevisiae nucleus. Journal of Proteomics, 72, 10-120. https://doi.org/10.1016/j.jprot. 2008.10.008

Nair, R. M., Yang, R.-Y., Easdown, W. J., Thavarajah, D., Thavarajah, P., Hughes, J., \& Keatinge, J. D. H. (2013). Biofortification of mungbean (Vigna radiata) as a whole food to enhance human health. Journal of the Science of Food and Agriculture, 93, 1805-1813. https://doi.org/10.1002/jsfa.6110

Neilson, K. A., Keighley, T., Pascovici, D., Cooke, B., \& Haynes, P. A. (2013). Label-free quantitative shotgun proteomics using normalised spectral abundance factors. In M. Zhou \& T. Veenstra (Eds.), Proteomics for Biomarker Discovery: Methods and Protocols, Methods in Molecular Biology (pp. 205-222). Springer Science+Business Media.

Nout, M. J. R., \& Ngoddy, P. O. (1977). Technological aspects of preparing affordable fermented complementary foods. Food Control, 8, 279-287. https://doi.org/10.1016/S0956-7135(97)00001-7

Patterson, C. A., Curran, J., \& Der, T. (2017). Effect of processing on antinutrient compounds in pulses. Cereal Chemistry, 94, 2-10. https://doi.org/10.1094/CCHEM-05-16-0144-FI

Pelgrom, P. J. M., Boom, R. M., \& Schutyser, M. A. I. (2015). Method development to increase protein enrichment during dry fractionation of starch-rich legumes. Food and Bioprocess Technology, 8, 1495-1502. https://doi.org/10.1007/s11947-015-1513-0

Podwojski, K., Eisenacher, M., Kohl, M., Turewicz, M., Meyer, H. E., Rahnenführer, J., \& Stephan, C. (2010). Peek a peak: A glance at statistics for quantitative label-free proteomics. Expert Reviews in Proteomics, 7, 249-261. https://doi.org/10.1586/epr.09.107

Prakash, D., Niranjan, A., Tewari, S. K., \& Pushpangadan, P. (2001). Underutilised legumes: Potential sources of low-cost protein. International Journal of Food Science and Nutrition, 52, 337-341. https://doi.org/ $10.1080 / 09637480120057521$

Rahma, E. H., Dudek, S., Mothes, R., Görnitz, E., \& Schwenke, K. D. (2000). Physicochemical characterisation of mungbean (Phaseolus aureus) protein isolates. Journal of the Science of Food and Agriculture, 80, 477-483. https://doi.org/10.1002/(SICI)1097-0010(200003)80:4\%3C477::AID-JSFA553\%3E3.0.CO;2-0

Singh, S., Singh, H. D., \& Sikka, K. C. (1968). Distribution of nutrients in the anatomical parts of common Indian pulses. Cereal Chemistry, 45, 13-18.

Skylas, D. J., Blanchard, C. L., \& Quail, K. J. (2017). Variation in nutritional composition of Australian mungbean varieties. Journal of Agricultural Science, 9, 45-53. https://doi.org/10.5539/jas.v9n5p45

Sun-Waterhouse, D., Zhao, M., \& Waterhouse, G. I. N. (2014). Protein modification during ingredient preparation and food processing: Approaches to improve food processability and nutrition. Food and Bioprocess Technology, 7, 1853-1893. https://doi.org/10.1007/s11947-014-1326-6

Tharanathan, R. N., \& Mahadevamma, S. (2003). Grain legumes-A boon to human nutrition. Trends in Food Science and Technology, 14, 507-518. https://doi.org/10.1016/j.tifs.2003.07.002

Thelen, J. J., \& Peck, S. C. (2007). Quantitative proteomics in plants: Choices in abundance. Plant Cell, 19, 3339-3346. https://doi.org/10.1105/tpc. 107.053991

Thompson, L. U. (1977). Preparation and evaluation of mungbean protein isolates. Journal of Food Science, 42, 202-206. https://doi.org/10.1111/j.1365-2621.1977.tb01252.x

Vaz Patto, M. C., Amarowicz, R., Aryee, A. N. A., Boye, J. I., Chung H.-J., Martín-Cabrejas, M. A., \& Domoney, C. (2015). Achievements and challenges in improving the nutritional quality of food legumes. Critical Reviews in Plant Sciences, 34, 105-143. https://doi.org/10.1080/07352689.2014.897907

Walker, A. F., \& Kochhar, N. (1982). Effect of processing including domestic cooking on nutritional quality of legumes. Proceedings of the Nutrition Society, 41, 41-51. https://doi.org/10.1079/PNS19820006

Wang, M., Jiang, L., Li, Y., Liu, Q., Wang, S., \& Sui, X. (2011). Optimisation of extraction process of protein isolate from mungbean. Procedia Engineering, 15, 5250-5258. https://doi.org/10.1016/j.proeng.2011.08.973 
Wang, W., Vinocur, B., Shoseyov, O., \& Altman, A. (2004). Role of plant heat-shock proteins and molecular chaperones in the abiotic stress response. Trends in Plant Science, 9, 244-252. https://doi.org/10.1016/ j.tplants.2004.03.006

Wang, Z., Han, F., Sui, X., Qi, B., Yang, Y., Zhang, H., ... Jiang, L. (2016). Effect of ultrasound treatment on the wet heating Maillard reaction between mungbean [Vigna radiate (L.)] protein isolates and glucose and on structural and physico-chemical properties of conjugates. Journal of the Science of Food and Agriculture, 96, 1532-1540. https://doi.org/10.1002/jsfa. 7255

Zeng, X., Li, Y.-F., \& Mahalingam, R. (2014). Arabidopsis nudix hydrolase 7 plays a role in seed germination. Planta, 239, 1015-1025. https://doi.org/10.1007/s00425-014-2035-0

Zhang, B., VerBerkmoes, N. C., Langston, M. A., Uberbacher, E., Hettich, R. L., \& Samatova, N. F. (2006). Detecting differential and correlated protein expression in label-free shotgun proteomics. Journal of Proteome Research, 5, 2909-2918. https://doi.org/10.1021/pr0600273

Zybailov, B. L., Florens, L., \& Washburn, M. P. (2007). Quantitative shotgun proteomics using a protease with broad specificity and normalised spectral abundance factors. Molecular BioSystems, 3, 354-360. https://doi.org/10.1039/b701483j

Zybailov, B., Mosley, A. L., Sardiu, M. E., Coleman, M. K., Florens, L., \& Washburn, M. P. (2006). Statistical analysis of membrane proteome expression changes in Saccharomyces cerevisiae. Journal of Proteome Research, 5, 2339-2347. https://doi.org/10.1021/pr060161n

\section{Appendix A}

\section{Flour specific proteins identified from a comparison of MWF and MDF}

\begin{tabular}{|c|c|c|c|}
\hline Identifier & SC & $\begin{array}{l}\text { Matching protein description } \\
\text { [Vigna radiata } \text { var. radiata }]\end{array}$ & NSAF \\
\hline \multicolumn{4}{|l|}{ MDF Specific } \\
\hline gi|951066306|ref|XP_014523923.1| & 405 & Beta-conglycinin, beta chain-like & 0.08168 \\
\hline gi|951006538|ref|XP_014508498.1| & 11 & Uncharacterised protein LOC106768046 & 0.00696 \\
\hline gi|951004779|ref|XP_014507957.1| & 5 & Uncharacterised protein LOC106767550 & 0.00372 \\
\hline gi|951042601|ref|XP_014518193.1| & 6 & Uncharacterised GPI-anchored protein At5g19250-like & 0.00243 \\
\hline gi|950966752|ref|XP_014499164.1| & 5 & Translationally-controlled tumor protein homolog & 0.00236 \\
\hline gi|951033740|ref|XP_014515808.1| & 19 & Heat shock $70 \mathrm{kDa}$ protein-like & 0.00235 \\
\hline gi| $950971152 \mid$ ref|XP_014500243.1| & 9 & Annexin-like protein RJ4 & 0.00229 \\
\hline gi|950933402|ref|XP_014511960.1| & 12 & Elongation factor 1-alpha & 0.00212 \\
\hline gi|951036864|ref|XP_014516740.1| & 6 & 40S ribosomal protein S6-like & 0.00208 \\
\hline gi|950943809|ref|XP_014493887.1| & 15 & Heat shock cognate $70 \mathrm{kDa}$ protein 2 & 0.00189 \\
\hline gi|950944995|ref|XP_014494154.1| & 7 & Malate dehydrogenase, mitochondrial & 0.00172 \\
\hline gi|950992302|ref|XP_014504685.1| & 13 & Heat shock cognate protein 80 & 0.00149 \\
\hline gi|950994103|ref|XP_014505054.1| & 6 & Glucose-1-phosphate adenylyltransferase small subunit 2, chloroplastic & 0.00100 \\
\hline gi|950953641|ref|XP_014496230.1| & 5 & Enolase & 0.00100 \\
\hline gi|951071101|ref|XP_014491069.1| & 5 & Uncharacterised protein LOC106753730 & 0.00058 \\
\hline gi|951062968|ref|XP_014523173.1| & 7 & Alpha-glucan water dikinase, chloroplastic & 0.00038 \\
\hline
\end{tabular}




\section{Appendix B}

Flour specific proteins identified from a comparison of MGF and MWF

\begin{tabular}{llll}
\hline Identifier & SC & $\begin{array}{l}\text { Matching protein description } \\
\text { [Vigna radiata } \text { var. radiata }]\end{array}$ & NSAF \\
\hline MGF Specific & & & 0.06115 \\
gi|951066306|ref|XP_014523923.1| & 243 & Beta-conglycinin, beta chain-like & 0.00585 \\
gi|951008854|ref|XP_014509123.1| & 8 & Pathogenesis-related protein 2-like & 0.00568 \\
gi|951006538|ref|XP_014508498.1| & 7 & Uncharacterised protein LOC106768046 & 0.00505 \\
gi|951072921|ref|XP_014491947.1| & 5 & Non-specific lipid-transfer protein 1-like & 0.00464 \\
gi|951001085|ref|XP_014506982.1| & 6 & Pathogenesis-related protein 2-like & 0.00400 \\
gi|950971152|ref|XP_014500243.1| & 12 & Annexin-like protein RJ4 & 0.00265 \\
gi|951036864|ref|XP_014516740.1| & 6 & 40S ribosomal protein S6-like & 0.00243 \\
gi|951068867|ref|XP_014489923.1| & 9 & Glyceraldehyde-3-phosphate dehydrogenase, cytosolic-like & 0.00242 \\
gi|950992302|ref|XP_014504685.1| & 17 & Heat shock cognate protein 80 & 0.00242 \\
gi|950944995|ref|XP_014494154.1| & 7 & Malate dehydrogenase, mitochondrial & 0.00237 \\
gi|950956929|ref|XP_014496954.1| & 15 & Heat shock cognate 70 kDa protein 2-like & 0.00172 \\
gi|951011572|ref|XP_014509821.1| & 5 & Annexin-like protein RJ4 & 0.00165 \\
gi|951057234|ref|XP_014521938.1| & 5 & Fructokinase-2-like & 0.00162 \\
gi|950953641|ref|XP_014496230.1| & 7 & Enolase & 0.00154 \\
gi|950933402|ref|XP_014511960.1| & 7 & Elongation factor 1-alpha & 0.00145 \\
gi|951034199|ref|XP_014515942.1| & 12 & Linoleate 9S-lipoxygenase-like & \\
MWF Specific & & & 0.01686 \\
gi|950973966|ref|XP_014500828.1| & 5 & Uncharacterised protein LOC106761773 \\
gi|950959908|ref|XP_014497548.1| & 6 & Protein SLE1 isoform X1 & 0.01158 \\
\hline
\end{tabular}

\section{Appendix C}

\section{Flour specific proteins identified from comparison of MDF and MRF}

\begin{tabular}{|c|c|c|c|}
\hline Identifier & SC & $\begin{array}{l}\text { Matching protein description } \\
\text { [Vigna radiata var. radiata] }\end{array}$ & NSAF \\
\hline \multicolumn{4}{|l|}{ MDF Specific } \\
\hline gi|951004779|ref|XP_014507957.1| & 5 & Uncharacterised protein LOC106767550 & 0.00372 \\
\hline gi|950966752|ref|XP_014499164.1| & 5 & Translationally-controlled tumor protein homolog & 0.00236 \\
\hline gi|951033740|ref|XP_014515808.1| & 19 & Heat shock $70 \mathrm{kDa}$ protein-like & 0.00235 \\
\hline gi|950971152|ref|XP_014500243.1| & 9 & Annexin-like protein RJ4 & 0.00229 \\
\hline gi|950943809|ref|XP_014493887.1| & 15 & Heat shock cognate $70 \mathrm{kDa}$ protein 2 & 0.00189 \\
\hline gi|950992302|ref|XP_014504685.1| & 13 & Heat shock cognate protein 80 & 0.00149 \\
\hline gi|951067792|ref|XP_014524384.1| & 6 & Seed biotin-containing protein SBP65-like & 0.00141 \\
\hline gi|950994103|ref|XP_014505054.1| & 6 & Glucose-1-phosphate adenylyltransferase small subunit 2, chloroplastic & 0.00100 \\
\hline gi|950953641|ref|XP_014496230.1| & 5 & Enolase & 0.00099 \\
\hline gi|951071101|ref|XP_014491069.1| & 5 & Uncharacterised protein LOC106753730 & 0.00058 \\
\hline gi|950963716|ref|XP_014498402.1| & 5 & Cell division cycle protein 48 homolog & 0.00049 \\
\hline gi|951062968|ref|XP_014523173.1| & 7 & Alpha-glucan water dikinase, chloroplastic & 0.00038 \\
\hline
\end{tabular}

\section{Copyrights}

Copyright for this article is retained by the author(s), with first publication rights granted to the journal.

This is an open-access article distributed under the terms and conditions of the Creative Commons Attribution license (http://creativecommons.org/licenses/by/4.0/). 